\title{
Uma Proposta para Ensinar os Conceitos de Campo Elétrico e Magnético: uma Aplicação da História da Física
}

A proposal for teaching the concepts of electric and magnetic field: an application of history of physics

\author{
Murilo de F. Magalhães, Wilma M. S. Santos, Penha M. C. Dias \\ Instituto de Física \\ Universidade Federal do Rio de Janeiro
}

Recebido em 25 de junho, 2001. Revisado em 3 de janeiro, 2002. Aceito em 6 de agosto, 2002.

\begin{abstract}
Neste trabalho, propomos uma forma alternativa para apresentar os conceitos de campo elétrico e magnético ao aluno do Ensino Médio, inspirada na teoria da Aprendizagem Significativa, de Ausubel e Novak. A História da Física - por apresentar os problemas que levaram à formulação de um dado conceito - mostra os elementos que dão significado ao conceito. Por isso, acreditamos que ela possa ser integrada ao processo de ensino-aprendizagem significativos, tendo papel fundamental na inclusão dos novos conceitos à estrutura cognitiva. Os resultados da aplicação desse método, no Colégio Pedro II, no Rio de Janeiro, são apresentados.
\end{abstract}

In this paper, we propose an alternative way to introduce the concepts of electric and magnetic fields to high school students, which is inspired by the theory of Meaningful Learning, by Ausubel and Novak. The History of Physics discloses the elements that give meaning to a concept, in so far as it presents the problems that led to the formulation of the concept. Therefore we believe that it can be brought into the process of meaningful teaching and learning, performing a fundamental role in the assimilation of new concepts to the cognitive structure. The results of the application of the method in Colégio Pedro II, in Rio de Janeiro, are presented.

\section{Introdução}

Fenômenos elétricos e magnéticos estão presentes em grande parte dos equipamentos que fazem parte do nosso dia a dia, tais como computadores, televisores, geladeiras, motores e até mesmo campaínhas. Portanto, a compreensão do eletromagnetismo tem fundamental importância para o entendimento do mundo cotidiano, conseqüentemente, para o que se chama "educação cidadã".

Pesquisas mostram que muitos alunos do Ensino $\mathrm{Su}-$ perior ainda apresentam dificuldades em lidar com os conceitos de campo elétrico e campo magnético, devido à abstração neles envolvida; esses conceitos, embora presentes no dia-a-dia, estão fora do nosso domínio concreto [1]. As dificuldades em entender o conceito de campo de força, encontradas por estudantes na faixa etária de 6 a 17 anos, são tratadas em [2], onde o método clínico de Jean Piaget é empregado para analisar algumas propriedades do conceito.

A dificuldade de aprendizagem de tais conceitos, no Ensino Médio, é ilustrada pela experiência de um de nós, no Colégio Pedro II, unidade Tijuca II, no Rio de Janeiro. Em uma aula introdutória sobre eletromagnetismo, ministrada a alunos do $3^{\circ}$ ano do Ensino Médio, estes tiveram grande dificuldade em compreender o conceito de campo. Nessa aula, ao invés de simplesmente mostrar a fórmula da força magnética, como é feito tradicionalmente, foi proposto que os alunos desenvolvessem o conceito de força através da noção de campo (no caso, o campo magnético). O resultado não foi satisfatório, devido à dificuldade de compreensão do conceito de campo. Em outra tentativa, seguiu-se um método diferente. Inicialmente, o campo gravitacional foi usado para introduzir uma idéia geral de campo; depois, fez-se uma apresentação da História da Física, associada à evolução dos conceitos de campo elétrico e campo magnético, similar à apresentada, abaixo, neste trabalho; pequenas experiências, como a ação de ímãs em limalhas de ferro, foram realizadas em sala de aula. O resultado dessa tentativa foi positivo: Cerca de $80 \%$ dos alunos obteve média igual ou superior a 7 , enquanto que, na primeira tentativa, cerca de apenas $20 \%$ alcançaram esse resultado.

Esses resultados mostram que o ensino dos conceitos de campo elétrico e magnético requer um tratamento 
mais elaborado do que os feitos na maioria dos livrostexto convencionais. Este trabalho tem como objetivo formular uma proposta para o ensino dos conceitos de campo elétrico e magnético, que possa contribuir para os textos teóricos. Para tal formulação, inspiramo-nos na aprendizagem significativa, de David Ausubel, Joseph Novak e J.Hanesian ([3], [4], [5]).

Inicialmente, elaboramos um questionário que apontasse concepções prévias dos alunos; esse questionário é baseado no tipo de perguntas exemplificadas por Novak e D. B. Gowin ([6], p.146). Utilizamos essas concepções, juntamente com a História da Física. Nosso pressuposto é que a História da Física pode ser um elemento facilitador de uma aprendizagem significativa, na medida em que funciona como organizador prévio ([4], [5]), como defendido na seção II, abaixo. Os textos em História da Física podem ser de um nível introdutório, como o de George Gamow [7], usado conjuntamente com um livro-fonte, como o de Morris Shamos [8] e o de William F. Magie [9].

Uma observação que se faz necessária é que este trabalho não pretende apresentar uma nova teoria em Psicologia do Aprendizado; pelo contrário, partimos de uma teoria, a de Ausubel, para fundamentar o trabalho. O desiderato é que essa teoria possa clarificar o papel da História da Física como organizador prévio, o que, também, explicaria seu sucesso no ensino de Física. O estudo de caso - os campos elétrico e magnético partiu da experiência pessoal de um de nós, em sala de aula, acima descrita; os bons resultados obtidos motivaram sua divulgação.

Finalmente, achamos relevante que os alunos percebam que os fenômenos eletromagnéticos estão presentes não somente no dia-a-dia deles, mas são essenciais em muitas pesquisas, atualmente em curso nos mais modernos laboratórios, realizadas de acordo com padrões científicos de pesquisa, internacionalmente adotados. Em particular, citamos pesquisas em Física Atômica e Molecular, desenvolvida no Instituto de Física da UFRJ, no acelerador de partículas do tipo Tandem [10]. Mostramos que, nos feixes (de partículas) produzidos no acelerador, a velocidade e a energia das partículas dependem de campos elétricos e magnéticos cruzados, aplicados conjuntamente.

\section{Aprendizagem significativa e história da física}

Um pressuposto deste artigo é que a História da Física se insere na abordagem de Ausubel. O conceito básico da teoria é o de aprendizagem significativa. Segundo Marco Antonio Moreira e Elcie F. Salzano Masini ([4], p.7):

[...] aprendizagem significativa é um processo pelo qual uma nova informação se relaciona com um aspecto relevante da estrutura de conhecimento do indivíduo. Ou seja, neste processo a nova informação interage com uma estrutura de conhecimento específica, a qual Ausubel define como conceitos subsunçores ou, simplesmente, subsunçores (subsumers), existentes na estrutura cognitiva do indivíduo. A aprendizagem significativa ocorre, quando a nova informação ancora-se em conceitos relevantes preexistentes na estrutura cognitiva de quem aprende.

Assim, o processo central da aprendizagem significativa é ([11], p.233) "a interação entre a estrutura cognitiva prévia do aluno e o material ou conteúdo de aprendizagem." Para tanto ([4], p.11),

Ausubel [...] recomenda o uso de organizadores prévios que sirvam de âncora para a nova aprendizagem e levem ao desenvolvimento de conceitos subsunçores que facilitem a apredizagem subseqüente. [...]. Organizadores prévios são materiais introdutórios apresentados antes do próprio material a ser aprendido. Contrariamente a sumários, que são ordinariamente apresentados ao mesmo nível de abstração, generalidade e inclusividade, simplesmente destacando certos aspectos do assunto, os organizadores são apresentados num nível mais alto. Segundo o próprio Ausubel, no entanto, a principal função do organizador prévio é a de servir de ponte entre o que o aprendiz já sabe e o que ele deve saber, a fim de que o material possa ser aprendido de forma significativa.

A pertinência da História da Física ao ensino da Física é discutida em [12]. A História da Física apresenta os problemas que levaram à formulação de um particular conceito; ela revela os ingredientes, lógicos ou empíricos, que foram realmente importantes nesse processo. Portanto, a História da Física clarifica conceitos, revelando-lhes o significado. Do ponto de vista da aprendizagem significativa, a História da Física, por revelar significados, é um legítimo organizador prévio, pois se ajusta à seguinte tarefa ([4], p.12):

A principal função dos organizadores é, então, superar o limite entre o que o aluno já sabe e aquilo que ele precisa saber, antes de poder aprender a tarefa apresentada. Permitem prover uma moldura ideacional para incorporação e retenção do material mais detalhado e diferenciado que se segue na aprendizagem, $[\ldots]$.

A História da Física seria justificada, pois, pelas mesmas razões pelas quais organizadores prévios se justificam ([11], p.236): 
Usando as palavras de Ausubel: "As razões para utilizar organizadores são principalmente: a) a importânicia de se ter idéias pertinentes e, por outro lado, adequadas já disponíveis na estrutura cognitiva para dar significado às idéias novas [...]; b) as vantagens em utilizar as idéias mais gerais e inclusivas de uma disciplina como idéias de consolidação ou inclusores (destacando-se, a idoneidade e a especificidade da sua pertinência, a sua maior estabilidade inerente o seu maior poder explicativo e a sua capacidade integradora); c) o fato de que eles mesmos [os organizadores] se proponham a identificar o conteúdo pertinente que já existe na estrutura cognitiva (e relacionar-se explicitamente), bem como indicar, de uma maneira explícita, a pertinência desse conteúdo com a sua pertinência própria em relação ao novo material de aprendizagem."

Finalmente, em ([11], p.235) são listadas condições necessárias para uma aprendizagem significativa; dentre elas,

[...] a significatividade lógica do novo material que é preciso aprender remete à estrutura interna desse material, que não deve ser nem arbitrária nem confusa para facilitar o estabelecimento de relações substanciais com os conhecimentos prévios dos alunos.
Ora, ao clarificar conceitos a História da Física contribui para a clarificação da significatividade lógica de conceitos. É essa qualidade que a torna um organizador prévio em potencial.

\section{Conhecimentos prévios}

Para verificar conhecimentos prévios dos alunos, acerca dos conceitos de campo, independentemente da forma como foram obtidos por eles, elaboramos seis questões. Com isso, acreditamos obter um ponto de partida para ensinar o conceito de campo de força. $\mathrm{O}$ questionário foi respondido por 120 alunos do Ensino Médio, do Colégio Pedro II, Unidade Tijuca, Rio de Janeiro.

\section{III.1. Questões}

1. Por que a Terra atrái os corpos para sua superfície?

2. Ímãs atraem-se ou se repelem? Por que?

3. Imagine-se perdido numa floresta e que você disponha, somente, de uma bússola. Você saberia usá-la?

4. Você já ouviu falar em campo elétrico ? A que você o associa?

5. Você já ouviu falar em campo magnético ? A que você o associa?

6. Você conhece algum fenômeno, em que os campos elétrico e magnético estejam presentes?

\section{III.2. Respostas}

\section{Questão 1}

Todos os alunos citaram a força da gravidade como causadora da atração dos corpos para a superfície da Terra.

\section{Questão 2}

$\begin{array}{cc}\text { Número de alunos } & \text { Porcentagem } \\ 84 & 70 \\ 11 & 9 \\ 13 & 11 \\ 12 & 10\end{array}$

Número de alunos

76

Porcentagem

16

64

13

28

\author{
Observações \\ Sabem o conceito de atração e repulsão \\ Só citaram a existência dos pólos do ímã \\ Confundiram pólos do ímã com cargas elétricas \\ Não conhecem os pólos e nem atração e repulsão
}

\section{Questão 3}

Observações

Saberiam usar uma bússola

Precisariam de maiores explicações para usar uma bússola

Não saberiam utilizar uma bússola

\section{Questão 4}

$\begin{array}{cc}\text { Número de alunos } & \text { Porcentagem } \\ 46 & 39 \\ 40 & 33 \\ 34 & 33\end{array}$

Observações

Associaram campo elétrico a carga elétrica

Já ouviram falar, mas não conseguiram fazer uma associação Nunca ouviram falar em campo elétrico 


\section{Questão 5}

$\begin{array}{cc}\text { Número de alunos } & \text { Porcentagem } \\ 44 & 37 \\ & \\ 52 & 43 \\ 24 & 20\end{array}$

\author{
Observações \\ Associaram campo magnético a magnetismo, ímãs e a \\ materiais magnéticos presentes em equipamentos \\ Já ouviram falar, mas não conseguiram fazer uma associação \\ Nunca ouviram falar em campo magnético
}

\section{Questão 6}

Nenhum dos alunos sabe da existência de fenômenos em que os dois campos estejam presentes.

\section{III.3. Avaliação}

Uma das dificuldades da abordagem de Ausubel é que $([6]$, p. 40)

ele não forneceu a educadores métodos funcionais simples que os ajudassem a estabelecer "o que o aprendiz já sabe".

As questões acima não pretendem ser o resultado de uma pesquisa que responda à crítica de Novak e Gowin. Nem foi possível aplicar o questionário, de novo, ao término do curso, por razões meramente burocráticas. No entanto, os alunos prestaram exame de conclusão da disciplina que, embora nos moldes tradicionais, teve suas questões baseadas nas do questionário. Assim, devido ao alto índice de aprovação entre os alunos, consideramos que as respostas fornecem alguma indicação. Os resultados podem ser divididos em três categorias:

(1) A porcentagem de acerto das respostas às questões 1,2 e 3 (acima da média) indica que os alunos estão familiarizados com a atração gravitacional, os conceitos de atração e repulsão magnética e a bússola.

(2) A porcentagem de acerto das respostas às questões 4 e 5 (abaixo da média) indica que há pouca familiaridade com os conceitos de campo elétrico e campo magnético.

(3) A resposta à questão 6 mostra total falta de conhecimento sobre a atuação conjunta dos campos elétrico e magnético. Embora os alunos possam estar familiarizados com vários fenômenos eletromagnéticos, não sabem que são eletromagnéticos.

Parece, pois, que as questões 1, 2 e 3 indicam conhecimentos prévios ou, mais tecnicamente, subsunçores. Nossa proposta é associar esse conhecimento com a História da Eletricidade e do Magnetismo, em busca da facilitação de uma aprendizagem significativa, tanto dos conceitos envolvidos nas questões 1, 2 e 3, bem como dos envolvidos nas restantes.

\section{Proposta para o ensino}

\section{IV.1. Catálogo historiográfico}

Não se trata, nesta seção, de desenvolver uma história dos conceitos de campo elétrico e campo magnético. O objetivo é tão somente o de catalogar eventos, questões e problemas que foram significativos para a formulação e fundamentação desses conceitos. Esses eventos, questões e problemas são propostos, pois, neste trabalho, como subsunçores para a aprendizagem significativa.

\section{Cargas e magnetos}

Eventos no desenvolvimento histórico que estabeleceram a existência e a ação de cargas e magnetos foram:

(1) Apesar de efeitos magnéticos serem conhecidos desde a Antigüidade, estudos sistemáticos podem ser datados a William Gilbert (1544-1603). Ele pesquisou a atração entre magnetos e, também, efeitos eletrostáticos produzidos pelo atrito de certos materiais.

(2) Otto von Guericke (1602-1686) realizou o seguinte experimento: Ele atritou uma peça de âmbar e, depois, encostou-a em dois corpos; então, aproximando os dois corpos, eles se repeliam.

(3) Charles du Fay (1698-1739) explicou os experimentos de von Guericke supondo dois tipos de eletricidade: resinosa e vítrea. A resinosa é a produzida, por exemplo, por âmbar atritado e borracha dura; a vítrea, por vidros ou mica atritados. Du Fay observou, ainda, que cargas do mesmo tipo se repelem e de tipos diferentes se atraem e que corpos neutros contêm partes iguais das duas espécies.

(4) Benjamin Franklin (1706-1790) supôs que a eletricidade fosse um fluido. Em sua teoria, havia um só fluido, correspondendo à eletricidade vítrea; a eletricidade resinosa seria a ausência de fluido. A corrente elétrica flui de um corpo com excesso de fluido para um sem esse fluido.

(5) A medida dos efeitos de atração e repulsão entre cargas elétricas foi feita por Charles Augustin de Coulomb (1736-1806). Para isso, ele inventou a balança de torção. Um esquema da balança pode ser visto em Gamow ([7], p.129). Essa balança consiste em uma barra leve, suspensa por uma linha muito fina e longa, com duas esferas em suas extremidades, que se equilibram como os pratos de uma balança. Quando não existem forças agindo sobre as esferas, a barra assume uma certa posição, dita de equilíbrio. Se uma das esferas for eletricamente carregada e se uma outra esfera carregada for posta em sua vizinhança, a força elétrica que age sobre a esfera móvel causa um movimento de rotação da barra, 
em torno do seu ponto de suspensão. Como a barra é muito fina, uma força agindo sobre a esfera, ainda que pequena, produz um desvio considerável da posição de equilíbrio da barra; o ângulo de rotação é proporcional à força. Carregando as esferas com cargas diferentes e variando a distância entre elas, Coulomb pôde verificar que as forças de atração e repulsão elétricas são diretamente proporcionais ao produto das cargas e inversamente proporcionais ao quadrado da distância entre elas.

(6) Para determinar experimentalmente a lei que expressa a ação dos "fluidos magnéticos" [8], Coulomb colocou uma agulha de material magnético em uma posição fixa e aproximou dessa agulha uma outra, feita, também, de material magnético. Ao variar a posição da segunda agulha, ele verificou que a força magnética também variava.

(7) Hans Christian Oersted (1777-1851) estabeleceu, por meios experimentais, que existe uma relação entre fenômenos elétricos e magnéticos. Ele mostrou que uma corrente elétrica em um fio é capaz de mover a agulha de uma bússola (Fig. 1).
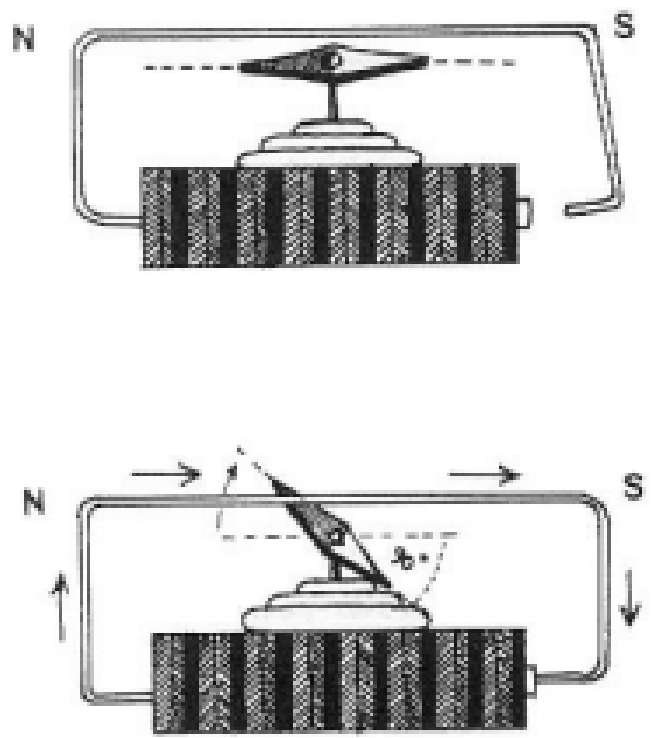

Figura 1. Experiência de Oersted: A figura ([7], p.135) ilustra as experiências descritas no texto. A agulha magnetizada é movida pela passagem da corrente no circuito.

\section{Os campos elétrico e magnético}

Era um pressuposto aceito que forças elétricas e magnéticas, assim como as forças gravitacionais, agem a distância, através do espaço vazio. Michael Faraday (1791-1867) criticou essa concepção. Em seu lugar, ele imaginou que o espaço entre cargas ou entre magnetos fosse preenchido por "algo" que empurrasse ou puxasse as cargas ou magnetos. Ele fez uma analogia entre esse "algo" e "tubos de borracha" que se "esticassem" entre cargas elétricas de sinais opostos ou pólos magnéticos de sinais opostos; ou se "contraíssem", quando as cargas tivessem sinais iguais ou os pólos, a mesma polaridade.
A Fig. 2a ilustra o caso de cargas e a Fig. 2b, o de magnetos.

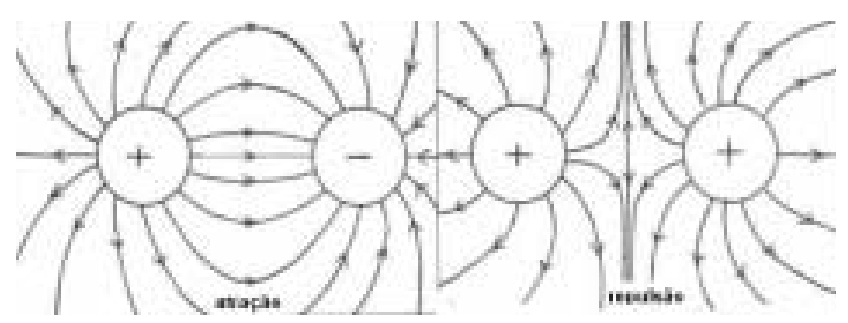

Figura 2a. Campo elétrico entre duas cargas: A figura ([7], p.150) mostra as linhas de campo (que Faraday imaginou serem "tubos") entre duas cargas. As linhas originam-se em cargas + e terminam em cargas - . A força elétrica e o campo elétrico são tangentes às linhas de campo.

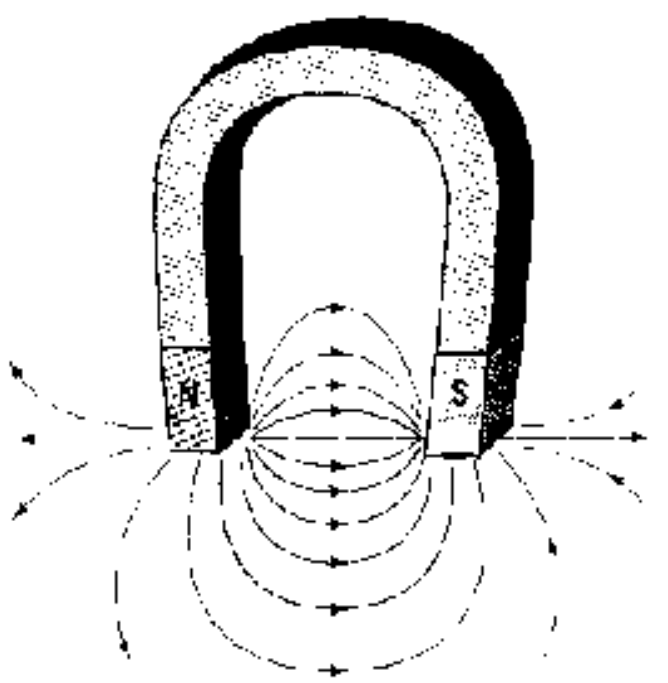

Figura 2b. Campo magnético entre dois pólos: A figura ([13], p.186) mostra as linhas de campo (que Faraday imaginou serem "tubos") entre dois pólos. As linhas originam-se no pólo Norte (N) e terminam no pólo Sul (S). O campo magnético é tangente à linha.

Os "tubos" elétricos e magnéticos foram usados por Faraday para explicar outros fenômenos eletromagnéticos:

- Quando uma corrente flui através de um fio, "tubos" circulares se formam em torno dele, de acordo com a Fig. 3.

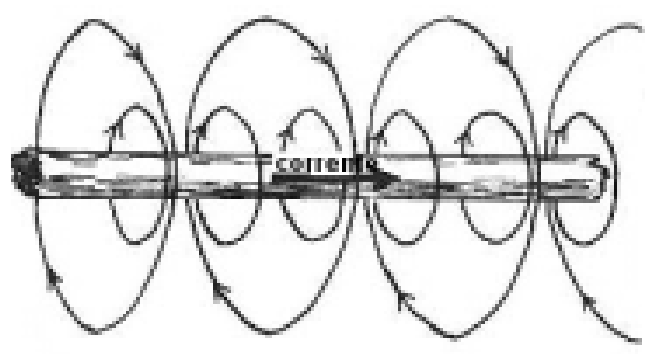

Figura 3. Campo magnético em torno de um fio onde passa corrente elétrica: A figura ([7], p.150) mostra as linhas de campo (que Faraday imaginou serem "tubos"). O campo magnético é tangente aos círculos, "girando", pois, 
em torno do fio; o campo é menor, quando o raio do círculo for maior. A força magnética é sempre perpendicular ao campo e à corrente, logo sua direção varia, quando o campo "gira".

- Quando um fio condutor é movido relativamente a um magneto, cruzando "tubos magnéticos", uma corrente é induzida no fio (Fig. 4).

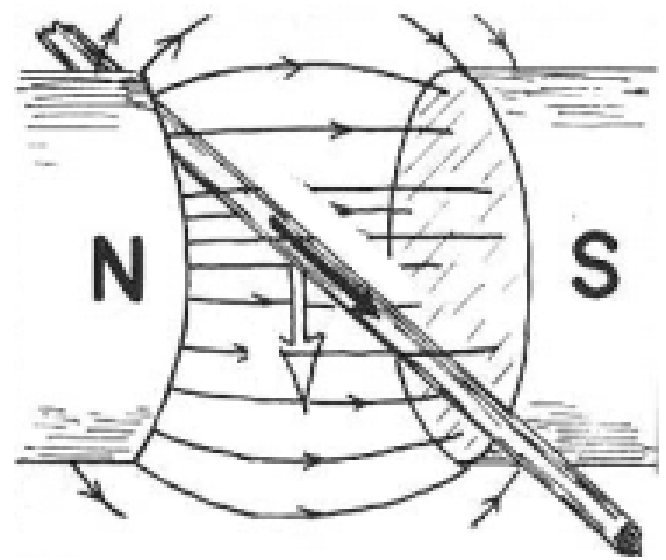

Figura 4. Lei de Faraday: A figura ([7], p.150) mostra o campo entre magnetos. Movendo o fio na direção da seta branca, de forma que ele "corte" as linhas, uma corrente se forma no fio, na direção da seta preta, ou seja, cargas existentes no material do fio movem-se, formando a corrente.

\section{IV.2. Os conceitos de força e campo}

Nesta seção, traçamos um roteiro para ensinar os conceitos de campo elétrico e magnético.

(1) A questão 1 foi respondida corretamente por todos os alunos. Portanto, a noção de campo pode ser ensinada aos alunos, fazendo-se uma analogia entre força gravitacional entre duas massas com a força elétrica entre duas cargas ou com a força magnética entre dois pólos de ímãs. Além dissso, as experiências de Coulomb mostram que os campos elétrico, magnético e gravitacional obedecem a leis similares, o que reforça a analogia.

(2) Embora a idéia de um "tubo" real, como uma conexão, seja errada, ela teve um valor heurístico fundamental na formulação do conceito de campo, na medida em que sugere um "algo" no espaço ao redor de uma carga ou um magneto, o que foi propriamente colocado por Gamow ([7], p.151):

Forças misteriosas agindo entre corpos, ao longo de grandes distâncias, foram substituídas por "algo" continuamente distribuído através de todo o espaço entre e em redor deles, "algo" ao qual poderia ser atribuído um valor definido em um ponto único. Isso introduziu na Física a idéia de um "campo de forças" ou simplesmente um "campo", fosse ele um caso de interação elétrica, magnética ou gravitacional.

Mais precisamente ([14], p.1-4):
É precisamente porque $\vec{E}$ [campo elétrico] (ou $\vec{B}$ [campo magnético]) pode ser especificado em cada ponto no espaço, que é chamado de "campo".

Além disso, os "tubos" permitem uma representação pictográfica dos campos e suas relações qualitativas com as forças:

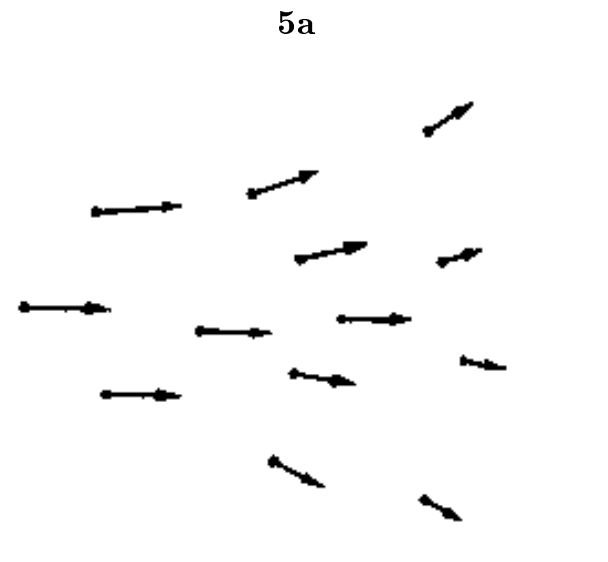

$5 \mathbf{b}$

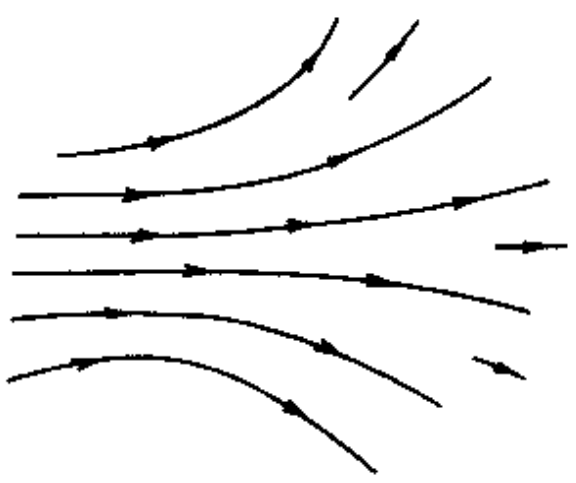

Figura 5. Representação de um Campo. As figuras ([14], 1-4) mostram o vetor campo em vários pontos do espaço (5a) e suas linhas de campo associadas (5b).

(i) De acordo com a Fig. 5b ([14],p.1-4):

Um campo de vetores pode ser representado, desenhando-se um conjunto de flechas, cujas grandezas e direções indicam os valores do campo de vetor nos pontos de onde as flechas são desenhadas.

(ii) De acordo com a Fig. 5b ([14], p.1-4):

Um campo de vetores pode ser representado, desenhando-se linhas tangentes à direção do vetor do campo em cada ponto e desenhando-se a densidade de linhas, proporcional à grandeza do vetor de campo.

(3) A expressão matemática do campo elétrico pode ser entendida pela expressão da força de Coulomb: 
módulo da força entre as cargas $q$ e $q_{1}$ :

módulo do campo elétrico de $q_{1}$ :

$$
\begin{gathered}
F_{\mathrm{el}}=k \frac{q q_{1}}{r^{2}} \\
F_{\mathrm{el}} \equiv q\left(\frac{k q_{1}}{r^{2}}\right) \\
E=\frac{k q_{1}}{r^{2}} \\
F_{\mathrm{el}}=q E, \quad \vec{F} \| \vec{E}
\end{gathered}
$$

(4) A Fig. 3 mostra o campo magnético causado por uma carga em movimento num fio: A direção do campo magnético, $\vec{B}$, em um ponto, é tangente ao círculo que passa pelo ponto.

(5) No caso dos magnetos, as direções do "campo" podem ser visualizadas, espalhando-se limalhas de ferro sobre uma lâmina de vidro, sobre a qual um magneto esteja colocado. As limalhas magnetizam-se e se orientam ao longo das "linhas de campo".

Na tentativa de ensino já mencionada na Introdução deste artigo, foi proposto aos alunos que realizassem uma experiência do mapeamento do campo de um ímã com limalhas de ferro; foram utilizados ímãs de vários formatos, por exemplo, círculo, botão, letra, colocados debaixo de uma folha de papel, sobre a qual limalhas de ferro foram espalhadas; assim, os alunos puderam observar as diferentes formas das linhas de força, formadas pelas limalhas sobre a folha. As "linhas" permitiram fazer uma analogia entre o que os alunos observaram concretamente, no experimento, e o conceito abstrato de campo.

(6) A Fig. 4 pode ser usada para ilustrar o que acontece com uma carga colocada em um campo magnético: O campo é tangente às linhas do desenho; se um fio for colocado entre os magnetos, como mostra a figura, e for puxado para baixo, de modo a se mover cruzando linhas de campo, no momento em que ele começa a se mover para baixo, uma carga no fio, inicialmente em repouso, sofre uma força na direção do fio, começando a se mover ao longo dele; ou seja, uma corrente é indu$z i d a$ no fio. Invertendo a leitura da figura, pode-se dizer que uma carga, movendo-se ao longo do fio, no campo magnético da figura, sofre uma força (magnética) para baixo (então, quando se coloca o fio em que passa uma corrente elétrica no campo, ele é puxado para baixo), ou seja:
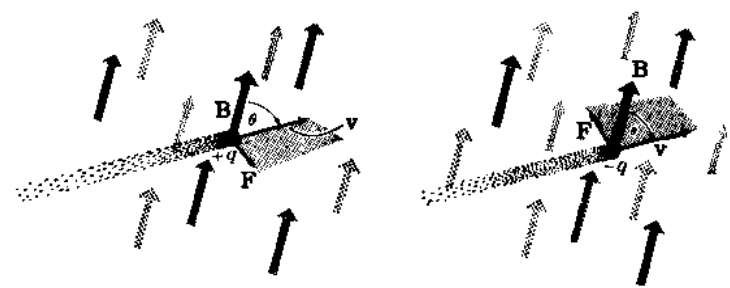

Figura 6. Força em uma Carga que se Move em um Campo Magnético. Uma carga positiva (figura da esquerda), $q$, movendo-se em um campo magnético, $\vec{B}$, sofre uma força magnética, $\vec{F}$, perpendicular ao plano de $\vec{v}$ e $\vec{B}$; uma carga negativa (figura da direita) sofre uma força na mesma direção e em sentido oposto da força sobre a carga positiva ([15], p.274). módulo do campo magnético: B

módulo da velocidade de $q$ : $\quad \mathrm{v}$ módulo da força magnética na carga $q: F_{\text {mag }}$ $\vec{F}_{\text {mag }} \perp \vec{v} \quad \vec{F}_{\text {mag }} \perp \vec{B}$

No caso das Figs. 4 e 6 , onde $\vec{v} \perp \vec{B}$, o módulo da força magnética é:

$$
F_{\text {mag }}=q v B
$$

(7) A atuação conjunta dos campos elétrico e magnético em uma carga em movimento pode ser ilustrada com um exemplo. Talvez haja exemplos mais potencialmente significativos, como o tubo de raios catódicos do aparelho de televisão; porém o exemplo foi particularmente escolhido para ilustrar aos alunos o uso sistemático desses campos na pesquisa moderna em Física Atômica e Molecular.

As forças magnética e elétrica atuam em partículas carregadas em movimento, tais como elétrons, prótons e íons. Uma conseqüência é que um campo elétrico e um campo magnético perpendiculares entre si permitem selecionar, pela velocidade, as partículas carregadas, que estão em um feixe. Esse fato é utilizado em numerosas aplicações físicas, como, por exemplo, o filtro de Wien, um dispositivo que separa as partículas de um feixe, de acordo com a massa.

O feixe é lançado numa região onde existe um campo magnético, $\vec{B}$, e um campo elétrico, $\vec{E}$, perpendicular a $\vec{B}$. Cada partícula fica submetida a uma força elétrica, de módulo $F_{\text {el }}=|q| E$, e a uma força magnética, de módulo $F_{\text {mag }}=|q| B v$. Os valores de $E$ e $B$ são ajustados de modo que $F_{\text {el }}=F_{\text {mag. }}$ Logo:

$$
|q| B v=|q| E \Rightarrow v=\frac{E}{B}
$$

O resultado significa que a resultante das forças é nula somente nas partículas com velocidade $v$; pela $L e i$ da Inércia, elas se deslocam em linha reta. Portanto, as partículas saem com a mesma energia cinética, quando extraídas do feixe:

$$
E_{\text {cin }}=\frac{1}{2} m v^{2} \Rightarrow v=\sqrt{\frac{2 E_{\text {cin }}}{m}} .
$$

Logo

$$
\frac{E}{B}=\sqrt{\frac{2 E_{\text {cin }}}{m}} \Rightarrow m=\frac{2 E_{\text {cin }} B^{2}}{E^{2}} .
$$


O campo magnético e a energia cinética são fixos. $\mathrm{O}$ campo elétrico depende da voltagem no terminal da fonte de íons: Quanto maior for a voltagem, maior o campo elétrico. Conseqüentemente, é possível selecionar a massa variando a voltagem, logo o campo elétrico.

\section{Conclusão}

Neste trabalho, apresentamos uma forma alternativa de abordar os conceitos de campo elétrico e magnético, visando melhorar a eficiência do processo de ensino-aprendizagem significativo desses conceitos; em particular, visamos os cursos de Física, no Ensino Médio. Nossa proposta baseia-se na opinião dos estudantes, como expressa pelas respostas ao questionário aplicado, e posterior análise do resultado.

De um lado, ressaltamos que o uso de conhecimentos prévios dos alunos para introduzir novos conceitos ou até mesmo teorias é uma prática que deve ser explorada enfática e sistematicamente; isso torna-se, ainda, muito mais fundamental, quando da iniciação ao estudo da Física, o que se dá no Ensino Médio. Por outro lado, a abordagem histórica parece ser uma ferramenta muito eficiente, pois possibilita melhor organização da estrutura conceitual, na medida em que revela as concepções que fundamentam um conceito ou até teorias.

O ensino de campo a partir da abordagem proposta neste trabalho produziu, na opinião dos autores, um desempenho satisfatório na compreensão dos conceitos: Embora as provas aplicadas tivessem seguido o modelo determinado pelo colégio, as questões foram relacionadas aos conceitos envolvidos no questionário e baseadas em problemas apresentados em [13] e, além disso, as experiências que foram propostas em sala também contaram como parte dessa avaliação; o índice de $80 \%$ de médias iguais ou superiores a 7 , já mencionado na Introdução, indica, pois, em nossa opinião, uma melhora no entendimento dos conceitos físicos envolvidos no questionário. Essa melhora em relação ao período da avaliação anterior, época da primeira tentativa de ensino, nos motiva a relatar a experiência, mesmo que o instrumento de análise de nossa proposta tenha sido, apenas, o resultado da prova. Consideramos, portanto, que os resultados são válidos dentro da avaliação possível.

\section{Referências}

[1] FARIAS, A.J.O. "Existem Dificuldades dos Alunos na Interpretação da Interação Carga-Campo?", Revista Brasileira de Ensino de Física, 21 (1999), 389-396.

[2] NARDI, R. e CARVAlHO, A.M.P. "Ensino do Conceito de Campo de Força", em NARDI, R. (Org.), Pesquisas em Ensino de Física, Escrituras Editora, 1998, 61-70.

[3] AUSUBEL, D., NOVAK, J.D., HANESIAN, H. Educational Psychology, a Cognitive View, Holt, Reinhart and Wiston, 1978.

[4] MOREIRA, M.A. e MASINI, E.F.S. A Aprendizagem Significativa. A Teoria de David Ausubel, Editora Moraes, 1982.

[5] MOREIRA, M.A. Construtivismo: Significados, Concepções Errôneas e uma Proposta, VIII Reunión Nacional de Educación en la Física, Rosario, Argentina, 1993.

[6] NOVAK, J.D. , GOWIN, D.B. Learning How to Learn, Cambridge University Press, 1986.

[7] GAMOW, G. The Great Physicists from Galileo to Einstein, Dover, 1988.

[8] SHAMOS, M.H. Great Experiments in Physics, Dover, 1987.

[9] MAGIE, W.F. A Source Book in Physics, McGraw-Hill, 1935.

[10] LUNA, H., MAGALHÃES, S.D., AQUADRO, J.C., MARTINS, M.H.P., SANTOS, W.M.S., JALBERT, G., COELHO, L.F.S., de CASTRO FARIA, N.V. "Electron Detachment of $\mathrm{Si}^{-}$by $\mathrm{He}, \mathrm{Ne}$, and Ar", Physical Review A, 63 (2001).

[11] SALVADOR, C.C. et al. Psicologia do Ensino, Editora Artes Médicas Sul, 2000. Traduzido do espanhol por Cristina Maria de Oliveira, Psicologia da la Instrucció, ediciones de la Universitat Oberta de Catalunya, 1997.

[12] DIAS, P.M.C. "A (Im)pertinência da História ao Aprendizado da Física (Um Estudo de Caso)", Revista Brasileira de Ensino de Física, 23 (2001), 226-235.

[13] GASPAR, A. Física, Editora Ática, 2000, 3 volumes; em vol.3, "Eletromagnetismo e Física Moderna".

[14] FEYNMAN, R.P., LEIGHTON, R.B. e SANDS, M. Lectures on Physics, Addison-Wesley, 1964, 3 volumes; em vol. 2, "Mainly Electromagnetism and Matter".

[15] FOWLER, R.G., MEYER, D.I. Physics (for engineers and scientists), Allyn and Bacon, Inc., 1958. 